\title{
Biological wastewater treatment and bioreactor design: a review
}

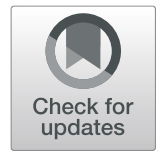

C. M. Narayanan ${ }^{*^{*}}$ and Vikas Narayan ${ }^{2}$

\begin{abstract}
Various processes that have been successfully developed for wastewater treatment (treatment of industrial wastes/ effluents) have been surveyed with special reference to biological treatment including design of bioreactors. Limitations of each process, design and performance characteristics of different kinds of bioreactors developed starting from stirred tanks to packed bed, fluidized bed, moving bed, semifluidized bed, inverse fluidized bed, sludge bed/sludge blanket and downflow stationary fixed film bioreactors have been highlighted. Utilization of membrane-based technology and liquid phase oxygen technology in wastewater treatment has also been analyzed. Both aerobic and anaerobic processes have been considered and possibilities of clubbing waste treatment with waste utilization (production of valuable products from waste streams) have also been surveyed and scrutinized.

Keywords: Biological wastewater treatment, Stirred tank bioreactors, Moving bed and packed bed bioreactors, Fluidized, Semifluidized and inverse fluidized biofilm reactors, DSFF and UASB bioreactors
\end{abstract}

\section{Introduction}

Biological wastewater treatment is a biochemical process that is centuries old. Even today, as the quantity of industrial effluents discharged is on the increase and the types of pollutants present in the effluent streams are getting diversified, wastewater treatment processes are being investigated and experimented exorbitantly all over the globe. It is always desirable to couple wastewater treatment with waste utilization. In such a situation, it becomes invariable to propose and develop renovations in effluent handling and treatment processes to improve their overall economy as well as their energy efficiency. This paper surveys the developments in biological wastewater treatment processes and in the design of bioreactors associated with.

\section{Stirred tank bioreactors for aerobic waste water treatment}

Activated sludge process, which involves aerobic treatment of industrial effluents in stirred tank bioreactors, is one among the very old industrial applications of biotechnology. Still this process is popular in spite of some

* Correspondence: prof.cmn@gmail.com

${ }^{1}$ National Institute of Technology, Durgapur 713209, India

Full list of author information is available at the end of the article of its inherent limitations. It is also the process that has been subjected to the maximum number of modifications and diversifications.

The conventional activated sludge process employs an aerobic tank which is an agitated vessel (stirred tank bioreactor) seeded with an inoculum of microbial sludge (usually the recycled portion of active sludge). Here, suspended growth of microbes occur. Air is sparged under high pressure from the bottom to provide sufficient dissolved oxygen in the medium. Since the volume of the aerobic tank is usually quite large and the solubility of atmospheric oxygen in water or aqueous solutions is very low, huge air compressors would have to be deployed to sparge in significant amount of air so as to meet the oxygen requirement of the microbes and that of the aerobic process. This high operating cost of air compressors forms the major economic limitation of this process, though the system is simple to design and install.

Apart from the oxidation of the dissolved organic matter (to carbon dioxide and water), nitrification and denitrification processes could also be conducted here. Nitrification is accomplished in the aerobic tank itself (simultaneously with carbon removal), during which the dissolved ammonia in wastewater is converted to nitrates. Denitrification, being an anoxic process, is 
conducted in a separate bioreactor. During denitrification, the nitrates formed during nitrification are reduced to nitrogen gas and thus is expelled from the bioreactor. Since the process is anoxic in nature, this bioreactor does not need supply of atmospheric air from outside.

As stated earlier, many modifications of activated sludge process have been proposed by different researchers during the past. A comprehensive survey of the same has been presented by Rao and Subramanyam [1]. Nevertheless, all the schemes employ stirred tank bioreactors. The conventional scheme involves two bioreactors (stirred tanks) in series, the first one being the aerobic tank in which carbon removal (organic matter destruction) and nitrification occur, while in the second denitrification is performed anoxically. The effluent from the denitrification tank is sent to a sedimentation tank for clarification; treated water overflows and the thickened bottom sludge is partially recycled back to the aerobic tank (stirred tank - 1). The amount of microbial sludge recycled must be optimized so as to minimize occurrence of endogenous decay of microbes, simultaneously maintaining the degree of biological oxygen demand (BOD) removal at a higher magnitude.

The so-called Bardenpho scheme [2] is a modified form of activated sludge process that employs four stirred tank bioreactors in series, the first one being a pre-denitrification bioreactor (stirred tank - 1) which is followed by the first aerobic tank (stirred tank - 2) and then the second denitrification bioreactor (stirred tank 3 ) and finally, the second aerobic tank (stirred tank - 4). The effluent from the last bioreactor is sent to the sedimentation tank and the separated sludge is partially recycled to stirred tank -1 . Such a scheme operates at high capacities, provides larger BOD removal, larger degree of denitrification and also larger phosphorus removal, but is more expensive to install, maintain and operate.

Instead of using a single stirred tank bioreactor, it is advisable to use a number of small size stirred tanks in series with the total volume of the cascade remaining the same as the single bioreactor. Such a scheme, which invariably improves the overall performance of the bioreactor, is achieved in activated sludge process by employing what is called as the step aeration $[1,2]$. The aerobic tank is divided into a number of compartments and each compartment receives a separate surge of compressed air. The raw wastewater is fed to the first compartment and the partially treated water flows to the subsequent compartments (from one compartment to the other), the product water (treated effluent) being discharged from the last compartment. The scheme does provide enhanced BOD destruction, though the overall operating cost also gets elevated. Since each compartment is quite small in size (volume) and is being aerated separately, the performance of each could approach ideal behavior (100\% back-mixing). In a single, large volume aerobic tank, dead zones and bypass streams could very well be present and these disturb the degree of backmixing and adversely affect the performance of the bioreactor.

It is further possible to use a series - parallel arrangement of stirred tanks in order to boost the performance of the bioreactor (aerobic tank) still further [3, 4]. In this case also, the aerobic tank is divided into a number of compartments and each compartment receives a part of the raw waste water (feed effluent) and is also aerated separately. Both step feeding as well as step aeration are thus employed here. Each compartment, except the first, receives a portion of the fresh feed as well as the partially treated effluent from the previous compartment. Such a scheme is well-recommended for large capacity installations. Here also, each compartment could perform equivalent to an ideal continuous stirred tank reactor (CSTR), providing intimate contacting between the substrate and the biocatalyst (microbial cells). The performance equation of each compartment then becomes

$$
\tau=\left(V / Q_{0}\right)=\left(C_{S 0}-C_{S e}\right) /\left(-r_{S e}\right)
$$

If the bioconversion (BOD destruction) follows Monod-type kinetics and the occurrence of endogenous decay (though minimal) is taken care of, then

$$
\left(-r_{S e}\right)=\left[\left(\mu_{m} / Y_{e}\right) C_{S e} x_{e} /\left(K_{S}+C_{S e}\right)\right]-\left(k_{d} x_{e}\right)
$$

The performance equation (Eq. 1) then becomes

$$
\tau=\left(C_{S 0}-C_{S e}\right)\left(K_{S}+C_{S e}\right) / F\left(C_{S}, x\right)
$$

where

$$
\begin{aligned}
& F\left(C_{S}, x\right)=\left(\mu_{m} / Y_{e}\right)\left(C_{S e} x_{e}\right)-\left(K_{S}+C_{S e}\right)\left(k_{d} x_{e}\right) \\
& Y_{e}=\text { true yield coefficient, } \mathrm{mg} \mathrm{mg}^{-1 .} \\
& k_{d}=\text { endogenous decay coefficient, } \mathrm{s}^{-1}
\end{aligned}
$$

Though in many cases of aerobic wastewater treatment, Monod-type kinetic equation has been observed to be more or less satisfactory, alternate kinetic models are not rare. For the aerobic synthesis of Xanthan gum from dairy wastes (for example, cheese whey) using a culture of Xanthomonas campestris, Zabot al [5]. report that the process follows Contois type kinetic equation:

$$
\left(-r_{S}\right)=\left(\mu_{m} / Y\right)\left(C_{S} x\right) /\left(K_{C} x+C_{S}\right)
$$

where $K_{C}=$ Contois kinetic constant

$Y=$ overall yield coefficient for cell mass production, $\mathrm{mg} \mathrm{mg}^{-1}$

As stated earlier, the most serious bottleneck associated with aerobic processes employing stirred tank bioreactors is the high operating cost of the air compressors. A good solution to this bottleneck is the 
deployment of Liquid Phase Oxygen (LPO) technology [3, 6]. A good number of case studies in this connection have been reported in literature (discussed subsequently in this paper). LPO technology involves addition of a calculated amount of hydrogen peroxide into the feed water prior to admitting into the bioreactor. This hydrogen peroxide releases nascent oxygen in solution which, being extremely reactive, meets the entire oxygen requirement of the microbes and that of the process. As a result, no atmospheric air shall be required to be supplied from outside and this eliminates the entire operating cost of huge air compressors. The diffusional resistance encountered during the dissolution of gaseous oxygen into the aqueous substrate becomes absent and no vigorous agitation of the substrate shall be required. The bioreactor operates essentially in the liquid phase and the two phase (gas-liquid) nature of reactor operation gets eliminated. The kinetics of microbial growth and substrate utilization gets modified since the specific growth constant $(\mu)$ becomes a function of the concentration of hydrogen peroxide in solution $\left(C_{N}\right)$ as well:

$$
\mu=\left[\left(\mu_{m} C_{S}\right) /\left(K_{S}+C_{S}\right)\right]\left[K_{N} /\left(K_{N}+C_{N}\right)\right]
$$

where $K_{N}=$ LPO utilization coefficient, $\mathrm{g} \mathrm{L}^{-1}$

The enormously high reactivity of nascent oxygen itself forms the most important safeguard with respect to LPO utilization. Hydrogen peroxide is to be added precisely as per the very calculated amount and any excess (even marginal) could destroy the microbial cells themselves. This explains why the commercial adaptation of LPO technology is fairly slow. The $\mathrm{H}_{2} \mathrm{O}_{2}$ requirement, nevertheless, is small (5-7 M).

It is possible (and is often advisable) to couple Membrane Based Technology with activated sludge process. The wastewater, after pretreatments (such as lime addition, coagulation, filtration and clarification), be fed to a reverse osmosis (RO) unit, from where reusable water is collected as the permeate. The $\mathrm{RO}$ concentrate is further subjected to biological treatment in the aerobic tank and denitrification bioreactor. Smith [7] has reported a successful case study in this regard and has demonstrated that the BOD removal, phosphorus removal and nitrogen removal can be adequately enhanced by coupling $\mathrm{RO}$ with the aerobic process. An economic analysis of such a scheme has been reported by Narayanan [8]. The operating pressure of the RO unit (the transmembrane pressure difference that is required to be maintained) and the useful life span of the polymeric membrane are the major considerations that affect the overall economy of RO system. Chances of membrane clogging and fouling are the additional headaches. Narayanan [8] reported that two-thirds of the wastewater could be recovered in the $\mathrm{RO}$ unit and the rest one-third of the total waste be subjected to biological treatment and in that case, the overall cost of production of treated water could go down to three- fourths of the conventional scheme. This is after including the cost of membrane replacement. Based on their laboratory studies, Thakura et al. [9] have demonstrated that deployment of a forward osmosisunit in the upstream and a nanofiltration unit in the downstream would help in attaining high degree of chemical oxygen demand (COD) removal (more than 97\%) from pharmaceutical wastewaters. The overall economy of the proposal is, nevertheless, to be analyzed keeping in mind the high operating cost of the nanofilters and the large quantity of wastewater that is required to be handled in industrial practices.

\section{Stirred tank bioreactors for anaerobic waste treatment}

As in the case of aerobic treatment of wastes, stirred tank bioreactors are the earliest and still one among the popular ones employed for anaerobic treatment of industrial, domestic and municipal wastes. Large capacity (large holdup) and ease of installation are the chief reasons for such a choice. Anaerobic biological treatment of wastes/effluents, particularly when carried out using a complex culture of acidogenic, acetogenic and methanogenic microbes, has the additional advantage that the organic matter is not simply destroyed, but converted into valuable products such as biogas (which is a mixture of principally methane and carbon dioxide). The anaerobic digested sludge could be directly used as a low grade nitrogenous biofertiliser or could be used for the manufacture of phosphatic biofertilizer (called Phosphate Rich Organic Manure) through biochemical pathway [10, 11]. The process of anaerobic digestion is however relatively slower. Also, the methanogenic microbes, being obligate in nature, are quite sensitive to the operating temperature and $\mathrm{pH}$ of the medium, the optimum values being $\mathrm{pH}=$ 7.0 and $\mathrm{T}=330-35^{\circ} \mathrm{C}$.

Anaerobic digestion could be performed at high temperature $\left(55-65^{\circ} \mathrm{C}\right)$ using thermophilic microbes as well. This helps in destroying the pathogens at a faster rate, but there shall be additional cost of installation of heating pipes and supply of heat from outside. The cost of extra energy input often tends to compensate the benefit of faster pathogen kill and increased methane production. Also, thermophilic microbes are relatively slower growing bacteria as compared to mesophilic. Unless waste heat is available such as in Combined Heat and Power systems, thermophilic treatment of wastes shall not be an attractive or beneficial proposition. A thermophilic pretreatment may, however, be given to the feed slurry in case pathogen destruction is of serious concern $[3,12]$. 
Most of the studies reported in literature on anaerobic digestion using mesophilic microbes, are those dealing with the use of alternate, multiple substrates [13-18]. Most of them have employed laboratory stirred tanks (chemostats) for conducting the experiments and practically all of them deal with suspended growth of microbes. Though these investigations do demonstrate the feasibility of biogas generation using anaerobic digestion of different substrates (single/multiple), the actual performance characteristics of industrial bioreactors in this connection have not been highlighted.

Momoh and Nwaogazie [13] have reported increased biogas yield when waste paper is co-digested with water hyacinth and cow dung. Samson and LeDuy [14] have demonstrated that addition of microalgae (algal mass) increases the rate of anaerobic digestion of domestic sewage sludge, peat hydrolysate and spent sulfite liquor and leads to higher biogas yield. Anaerobic co-digestion of microalgae with waste paper has been investigated by Yen and Brune [15] and with waste activated sludge (WAS) by Costa et al. [16] and Yuan et al. [17]. Studies on co-digestion of microalgae with municipal food waste are reported by Krustok al [18]. and those with sewage sludge by Olsson et al. [19]. In all the cases, addition of algal mass has been found to be beneficial in boosting the rate of digestion and the yield of biogas. Ajeej et al. [20-22] report that anaerobic co-digestion of multiple substrates such as sewage sludge and waste paper with waste grown algae provides significantly larger biogas yield. When used as a single substrate, sewage sludge, waste paper and algal mass provided an average biogas production of 120,275 and $200 \mathrm{~mL} \mathrm{~d}^{-1}$ respectively, but when co-digestion of all the three substrates was performed, the biogas yield increased to 550 to $600 \mathrm{~mL} \mathrm{~d}^{-1}$.

Reported kinetic studies on anaerobic digestion [12, 23] have indicated that substrate inhibition to microbial growth is not unlikely in these processes, particularly when conducted in stirred tank bioreactors. Accordingly, a Haldane-Andrews type kinetic equation has been found to be most applicable here:

$$
\left(-r_{S}\right)=(\mu / Y) x
$$

where

$$
\mu=\left(\mu_{m} C_{S}\right) /\left[K_{S}+C_{S}+C_{S}^{2} / K_{S i}\right]
$$

$K_{S i}=$ substrate inhibition coefficient, $\mathrm{g} \mathrm{L}^{-1}$

Endogenous decay of microbes is little reported in these processes. Most probable reason is that the sludge is continuously discharged from the bioreactor almost at the same rate at which the fresh feed is admitted and recycle of microbial sludge is little practiced in these systems.
Graef and Andrews [23] have presented a detailed parametric analysis of the performance of anaerobic stirred tank bioreactor. They have however assumed the bioreactor to be equivalent to an ideal CSTR that receives a sterile feed. Accordingly,

$$
\tau=(1 / \mu)
$$

Though the process involves a complex culture of microbes (hydrolytic microbes, acidogens, acetogens, methanogens), the last step of conversion of acetic acid (or acetates) to methane and carbon dioxide (catalyzed by methanogens) is reported to be the slowest and thereby the rate controlling step [23]. As a result, acetic acid is considered as the limiting reactant and the kinetic equation (Eq. (8)) is expressed in terms of the concentration of unionized acetic acid in solution, $C_{A}$. Thus,

$$
\mu=\left(\mu_{m} C_{A}\right) /\left[K_{S}+C_{A}+C_{A}^{2} / K_{S i}\right]
$$

Based on the ionization constant $\left(K_{a}\right)$ of acetic acid and the equilibrium constant $\left(K_{1}\right)$ for carbon dioxide dissolution in the aqueous slurry (only $\mathrm{CO}_{2}$ dissolves in the aqueous phase, all the methane produced gets transferred to the gas phase),

$$
C_{A}=\left(K_{1} C_{g L} C_{S e}\right) /\left[K_{a}\left(C_{\mathrm{N} 0}-C_{S e}\right)\right]
$$

where $C_{S e}=$ total concentration of acetic acid in solution (free acid plus acetate)

$C_{g L}=$ concentration of carbon dioxide in solution

$C_{N O}=$ concentration of ammonia in solution (assumed to be more or less constant)

The net rate of production of carbon dioxide in solution $\left(R_{C}\right)$ shall be the difference between the rate of production of $\mathrm{CO}_{2}$ by microbial activity and the rate at which $\mathrm{CO}_{2}$ gas is being transferred to the gas space. Then, since $\tau=\left(C_{g L} / R_{C}\right)$,

$$
\begin{aligned}
& \tau=C_{g L} /\left[Y_{C}\left(\mu x_{e}\right)-\left(k_{L} a\right)\left(C_{g L}-C_{g L}^{*}\right)\right] \\
& =C_{g L} /\left[Y_{C}\left(x_{e} / \tau\right)-\left(k_{L} a\right)\left(C_{g L}-H e p_{C}\right)\right]
\end{aligned}
$$

where $Y_{C}=$ yield coefficient for the production of $\mathrm{CO}_{2}$, mol mol${ }^{-1}$

$k_{L}=$ liquid phase mass transfer coefficient, $\mathrm{m} \mathrm{s}^{-1}$

$a=$ specific interfacial area for mass transfer, $\mathrm{m}^{2} \mathrm{~m}^{-3}$

$\mathrm{He}=$ Henry's law constant, mole $\mathrm{L}^{-1} \mathrm{kPa}^{-1}$

$p_{C}=$ partial pressure of carbon dioxide in the gas space, $\mathrm{kPa}$

If $Q$ is the rate of production of biogas (in $\mathrm{m}^{3} \mathrm{~s}^{-1}$ ) and if $C_{g}$ is the molar concentration of $\mathrm{CO}_{2}$ in the gas space $\left(C_{g}=p_{C} / R T\right)$,

$$
Q\left(p_{C} / R T\right)=\left(k_{L} a\right)\left(C_{g L}-H e p_{C}\right) V
$$

Also, 


$$
\begin{aligned}
\left(Q \rho_{g}\right) & =Q(P / R T) \\
& =\left[\left(k_{L} a\right)\left(C_{g L}-H e p_{C}\right)+Y_{m}\left(\mu x_{e}\right)\right] V
\end{aligned}
$$

where $Y_{m}=$ yield coefficient for the production of methane, $\mathrm{mol} \mathrm{mol}^{-1}$

$\rho_{g}=$ molar density of biogas, $\mathrm{mol} \mathrm{m}^{-3}$

Clubbing the above two equations together, we get

$$
\left(Y_{m} x_{e} / \tau\right)\left[p_{C} /\left(P-p_{C}\right)\right]=\left(k_{L} a\right)\left(C_{g L}-H e p_{C}\right)
$$

The gas mixture (biogas) has been assumed to be following ideal gas behavior and the dissolution of $\mathrm{CO}_{2}$ in liquid, Henry's law. The above Eqs. (9), (10), (12) and (15) are solved simultaneously to estimate $\tau$ and thereby the volume of bioreactor $(V)$ required to affect the desired degree of BOD or VS destruction. In spite of the simplifying assumptions involved, the above model proposed by Graef and Andrews [23] does predict reliable results in specific number of cases.

Agitation of the substrate slurry is one of the operational problems encountered in stirred tank bioreactors. Introduction of mechanical impeller is problematic since this could cause leakage of atmospheric air into the bioreactor and escape of biogas produced. One of the earliest practices such as dividing the bioreactor into two compartments using a submerged partition does help on occasions. The feed slurry flows down into the first compartment, flows over the partition, enters into the second compartment and finally flows out as digested sludge into the outlet tank (sludge tank). This tortuous transit of the substrate slurry induces turbulence and mixing within the slurry. When a floating gas holder is used, its longitudinal movement also induces a degree of agitation into the substrate [24, 25].

An alternative proposed in this connection is partial recirculation of biogas into the bioreactor after enrichment. Bubbling of raw biogas through the substrate slurry, though creates a large degree of agitation, shall not be desirable since this would promote dissolution of $\mathrm{CO}_{2}$ in the aqueous slurry and thereby lower the $\mathrm{pH}$ of the medium and this could adversely affect the activity of methanogenic microbes. The biogas must be therefore first enriched, in a sense that its $\mathrm{CO}_{2}$ content must be reduced to a minimum and thereafter, a part of it could be bubbled through the substrate under pressure to induce agitation and turbulence. $\mathrm{CO}_{2}$ content of biogas can be removed efficiently by absorbing in aqueous monoethanolamine (MEA) solution in countercurrent packed towers [26]. Aqueous MEA not only absorbs $\mathrm{CO}_{2}$, but also reacts with it (chemisorption). Consequently, the rate of absorption is quite large and Narayanan and Bhattacharya [26] have reported that more than $98 \%$ of $\mathrm{CO}_{2}$ removal is possible within a packed height of $1.5 \mathrm{~m}$ in a $0.5 \mathrm{~m}$ diameter countercurrent packed tower. The rich MEA solution containing the dissolved $\mathrm{CO}_{2}$ is sent to a desorption tower (steam stripper) where the absorbed $\mathrm{CO}_{2}$ is stripped off by passing high pressure steam. The resulting lean MEA solution containing very little dissolved $\mathrm{CO}_{2}$ is recycled back to the top of the absorption tower. Such a scheme shall be acceptable in high capacity installations (in commercial biogas plants).

Enrichment of biogas is desirable (in fact, essential) when the same is being used for large scale, commercial applications. Once converted to more or less pure methane, it can be used in automobiles as a substitute to compressed natural gas or liquefied natural gas. It could be used as a furnace fuel and also for the manufacture of synthesis gas (by steam-hydrocarbon reaction). Once syngas is produced, a host of chemicals including fertilizers could be synthesized. Synthesis of liquid fuels (by the reputed Fischer Tropsch Synthesis) is another option $[26,27]$.

When being used on commercial scale, hydrogen sulfide is another possible contaminant in biogas which raises serious concern. Even if present at low concentrations, $\mathrm{H}_{2} \mathrm{~S}$ could cause serious corrosion problems in automobiles, boilers, furnaces, etc. and also could contaminate the syngas produced. Since the $\mathrm{H}_{2} \mathrm{~S}$ concentration is quite small, its removal in absorption towers shall not be efficient neither economical. A biochemical pathway $[10,28]$ has been recommended in this connection. The process employs two reactors, reactor 1 being a chemical reactor, while reactor 2 an aerobic bioreactor. In reactor 1 , the biogas containing $\mathrm{H}_{2} \mathrm{~S}$ is bubbled through ferric sulfate solution, wherein $\mathrm{H}_{2} \mathrm{~S}$ is oxidized to elemental sulfur (colloidal sulfur), while ferric sulfate is reduced to ferrous sulfate and sulfuric acid. The precipitated sulfur is separated by filtration and the acidified solution of ferrous sulfate is fed to the second reactor (aerobic bioreactor). Here, in the presence of a recombinant microbial culture of Thiobacillus ferrooxidant, ferrous sulfate is oxidized back to ferric sulfate and it is then recycled back to reactor 1 . The process is reported to be efficient even if $\mathrm{H}_{2} \mathrm{~S}$ concentration in biogas is low. It has the additional advantages such as both reactors operate at ordinary temperature and pressure, no valuable chemical is consumed and does not demand any chemical catalyst.

\section{Packed bed biofilm reactors for wastewater treatment}

Biofilm reactors employ attached growth of microbes. They are multiphase reactors dealing with heterogeneous systems. These bioreactors employ support particles (with an exception of down-flow stationary fixed film (DSFF) bioreactors, discussed subsequently) such as silica granules, polymer beads, activated carbon particles, etc. Each particle is surrounded by microbial cells 
forming a thin biofilm. These particle-biofilm aggregates form the discrete phase in these bioreactors. If $d_{P}$ is the diameter of the support particle and $\delta$ is the thickness of the biofilm surrounding it, then the diameter of each aggregate $\left(d_{P m}\right)$ shall be

$$
d_{P m}=\left(d_{P}+2 \delta\right)
$$

The density $\left(\rho_{S m}\right)$ of each aggregate shall be

$$
\rho_{S m}=f \rho_{m}+(1-f) \rho_{S}
$$

where $f=$ volume fraction of biofilm in aggregate

$$
=1-\left(d_{P} / d_{P m}\right)^{3}
$$

$\rho_{S}, \rho_{m}=$ density of support particle and that of microbial cells, respectively

Microbial cells do grow and multiply within the biofilm, but when the thickness of the biofilm increases beyond a certain value (usually, $\delta=0.3-0.5 \mathrm{~mm}$ ), the film gets detached from the particle surface and falls out (called sloughing) to be replaced by fresh cells and henceforth, the biofilm thickness remains more or less constant throughout the operation of the bioreactor. Also, as cells undergo death or decay, the dead cells fall out from the film and they are also fast replaced by fresh living cells. The cell mass concentration in the biofilm $\left(x_{f}\right)$ also thus remains more or less constant due to this. Since the volume of the biofilm is quite low, the magnitude of $x_{f}$ shall be significantly high and this helps in attaining high rate of bioconversion. Since neither the unconverted substrate nor the product formed tends to accumulate in the biofilm, both substrate inhibition and product inhibition to microbial growth shall be at a very low degree in these bioreactors. Bioconversion occurs predominantly in the biofilm, very little in the fluid bulk.

Since the system is multiphase and heterogeneous, additional substrate diffusional resistance comes into play which is accounted for by the effectiveness factor $(\eta)$. The actual rate of bioconversion (the global rate) shall be then equal to the product of the intrinsic rate and the effectiveness factor:

$$
\left(-r_{S}\right)=\eta\left(-r_{S}\right)(\text { int })
$$

Typically, the magnitude of $\eta$ ranges from 0.60 to 0.90 . Since $\eta$ is a complex function of the effective dimension of particle-biofilm aggregate $\left(L^{*}\right)$, the effective diffusivity $\left(D_{e}\right)$ of substrate into the biofilm and the kinetic constants governing the intrinsic rate of bioconversion, many researchers tend to neglect its influence and assume $\eta=1.0$, thereby inducing lot of approximation into the analysis/design procedure. If the bioconversion intrinsically follows Monod-type kinetics, then an estimate of $\eta$ could be made as [12],

$$
\eta=a-\tanh (\varnothing)\left[b \operatorname{coth}\left(\eta_{d}\right)-1\right] / \varnothing
$$

where

$$
\begin{aligned}
& \eta_{d}=(\sqrt{2} / \varnothing)((1+\beta) / \beta) \sqrt{\beta-\ln (1+\beta)} \\
& \beta=\left(C_{S P} / K_{S}\right)
\end{aligned}
$$

$\varnothing=$ Thiele-type modulus

$$
=L^{*} \sqrt{\mu_{m}(\text { app }) /\left(D_{e} K_{S}\right)}
$$

$L^{\prime \prime}=$ characteristic dimension of particle-biofilm aggregate

$$
\begin{gathered}
=\left(d_{P m}^{3}-d_{P}^{3}\right) /\left(6 d_{P m}^{2}\right) \\
\quad a=1, b=\eta_{d}, \text { if } \eta_{d} \leq 1 \\
a=\eta_{d}, b=1, \text { if } \eta_{d} \geq 1 \\
\mu_{m}(\operatorname{app})=\left(\mu_{m} / Y\right) x_{f} f\left(1-\epsilon_{P}\right) / \epsilon_{P L} \\
\epsilon_{P}=\left(\epsilon_{P L}+\epsilon_{P g}\right) \\
=\text { total voidage of the packed bed }
\end{gathered}
$$

$\epsilon_{P L}, \epsilon_{P g}=$ fractional liquid holdup and fractional gas holdup respectively in the packed bed

Studies have however indicated that the above semiempirical correlation often predicts distinctly larger values of $\eta$, thereby leading to occasional overestimation of bioreactor performance [3]. A modified correlation proposed by Gottifredi and Gonzo [29] is reportedly more dependable:

$$
(1 / \eta)^{2}=\left(1 / \eta_{d}\right)^{2}+\exp \left[\varnothing_{b}-\left(1 / \eta_{d}\right)^{2}\right]
$$

where

$$
\varnothing_{b}=6 \varnothing^{2} /\left\{5(1+\beta)^{2}\right\}
$$

For all alternate kinetic models (Haldane-Andrews model, Contois model and the like), the value of $\eta$ may be computed from the generalized relationship (definition) as given below (the integral being evaluated numerically):

$$
\eta=([3 \varnothing / \tanh (3 \varnothing)]-1) / 3 \varnothing^{2}
$$

where

$$
\begin{aligned}
& \varnothing=L^{*}\left(-r_{S}\right)(i n t) /\left[2 D_{e} I\right]^{1 / 2} \\
& I=\int_{0}^{C_{S P}}\left(-r_{S}\right)(\text { int }) d C_{S}
\end{aligned}
$$

Biofilm reactors are characterized by the mode of handling the particle-biofilm aggregates. One of the simplest (and earliest) means of handling these aggregates is in the form of a packed (fixed) bed. An example is the 
trickle bed biofilm reactor, which are one among the oldest processes used for aerobic wastewater treatment (as old as activated sludge process). This bioreactor employs downflow of feed water (under gravity) through the bed of particle-biofilm aggregates. Consequently, its operating cost is low. However, since the feed water is being made to trickle down the bed at low velocities, the capacity of the reactor also is low unless constructed in large diameters. The reactor is kept open so that atmospheric air could diffuse into the substrate solution and no air compressors are used. However, when valuable products are to be recovered from industrial wastes through aerobic biological processes, for example for the synthesis of Xanthan gum from dairy wastes (cheese whey), more or less sterile air would have to be supplied and in such cases, the bioreactor cannot be kept open and compressed sterile air would have to be sparged from the bottom.

Trickle bed bioreactors that are employed for aerobic wastewater treatment have been designed mainly based on experimental test data [30]. Such an approach, apart from being too empirical, diminishes the versatility of the reactor. Narayanan [31] has reported design and analysis of these bioreactors by assuming them to be equivalent to plug flow reactors. Such an assumption does induce a degree of approximation. A more accurate approach would be to model the bioreactor as equivalent to a plug flow dispersion reactor (PFDR) with a given value of axial dispersion coefficient $[3,32]$ and then solve the governing performance equation numerically. For example, based on the PFDR approach,

$$
\begin{aligned}
& -U_{L}\left(d C_{S} / d z\right)+D_{L P}\left(d^{2} C_{S} / d z^{2}\right) \\
& \quad=\eta\left(-r_{S}\right)(\text { int })
\end{aligned}
$$

where $D_{L P}=$ axial dispersion coefficient

$$
U_{L}=U(\sup ) / \epsilon_{\mathrm{PL}}
$$

Upflow anaerobic packed bed biofilm reactors can also be analyzed in a similar way. When there is gas evolution during the process, it becomes a three phase system and the three phase nature of the bioreactor would have to be adequately taken care of. In many cases, the gas is assumed to be executing dispersed flow in the form of very tiny bubbles and thus does not disturb the diffusion of substrate into the biofilm. The fractional gas holdup and fractional liquid holdup in the bed are nevertheless to be estimated separately from available experimental correlations [33-36].

\section{Moving bed biofilm reactors (biofilm slurry reactors) for wastewater treatment}

The terminology "moving bed biofilm reactors", commonly employed in association with wastewater treatment, is, in fact, a misnomer. It is not a column reactor (like a circulating fluidized bed or a column reactor in which the particles and the fluid move counter-currently) and it does not contain a particle bed. It is a stirred tank bioreactor which is fed with the particle-biofilm aggregates and these aggregates remain suspended in the substrate solution (wastewater) present in the stirred tank. In the aerobic process, the compressed air that is sparged under pressure from below keeps these aggregates in suspension. Due to the agitation provided by the air stream, these aggregates tend to move within the liquid bulk and that is why the term moving bed biofilm reactors has been assigned to these systems. However, it would be more appropriate to call them as "biofilm slurry reactors".

The system is heterogeneous, multiphase and the microbes undergo attached growth. There is no need of recycle of sludge, since the microbial cells remain attached to the support particles and do not leave the bioreactor. These bioreactors are best operated batch-wise, though continuous operation is not unusual. In the continuous mode of operation, the product solution with suspended particle-biofilm aggregates leaves the bioreactor and in that case, these aggregates would have to be separated (in a settling tank) and recycled back to the stirred tank. The degree of bioconversion (BOD removal) attained shall be higher since, as stated earlier, the biomass concentration in the biofilm shall be substantially high, though there shall be added resistance to substrate transfer into the biofilm (taken care of by the effectiveness factor, $\eta$ ).

Both the aerobic tank and the denitrification bioreactor of activated sludge process could be operated as moving bed biofilm reactors. Based on an ideal CSTR assumption, the performance equation (Eq. (3)) of the bioreactor is modified as:

$$
\tau=\left(C_{S 0}-C_{S e}\right)\left(K_{S}+C_{S e}\right) /\left[\mu_{m}(\text { app }) C_{S e}\right]
$$

where

$$
\mu_{m}(\text { app })=\eta\left(\mu_{m} / Y\right) x_{f} f(1-\epsilon) / \epsilon
$$

$(1-\epsilon)=$ volume fraction of particle-biofilm aggregates in suspension

Reported studies [37, 38], though on laboratory scale, have demonstrated that more than 90\% COD removal and more than $95 \%$ dephenolization are possible using these bioreactors of relatively lower size (as compared to those employed in activated sludge process) and they have also been found to be suitable for anaerobic and anoxic operations $[38,39]$. There is a comparative reduction in operating cost, though at large capacities, they do not compare favorably with column reactors. Also, when the degree of agitation is large, the biofilm tends to get detached from the particle surface. 
Use of biological flocs in stirred tank bioreactors is another option. Microbial cells do have a tendency to flocculate and thereby form flocs or aggregates. This tendency has been observed to be significant with filamentous and floc forming bacteria. The process is slow and it could take days or even weeks to form flocs of appreciable sizes (close to $1 \mathrm{~mm}$ ). These flocs are not to be confused with sludge granules (discussed subsequently in this paper). Apart from the long time period required for the formation of sizeable flocs, the overall stability of these flocs is another parameter of concern. Vigorous agitation of the substrate slurry often tends to disintegrate the flocs and this disturbs the overall operational stability of the bioreactor.

It is also possible to immobilize microbial cells in porous carriers and then use in stirred tanks. Such carriers are relatively more stable and in the immobilized state, microbes exhibit improved activity. They also possess reasonably large life span and large scale deactivation of microbes within these carriers has been observed to be absent. Scope for future research is quite bright in this area.

\section{Fluidized bed biofilm reactors for treatment of industrial wastes/effluents}

For large capacity installations, fluidized bed biofilm reactors are more recommended, since these bioreactors can be operated at much higher fluid velocities/flow rates [40]. The effluent from industries is admitted from the bottom of the column at a velocity much higher than the minimum fluidization velocity, but lower than the terminal free settling velocity of each particle-biofilm aggregate. Consequently, all aggregates remain suspended (fluidized) in the ascending stream of substrate solution. Since each aggregate is fully surrounded by the substrate (there is no channeling), the contacting between the two is more intimate and this improves the bioreactor performance. Also, as the bed expands (the expanded bed height, $L_{f}$ being decided by the operating fluid flow rate employed), the total active volume of the reactor also increases. Another interesting feature regarding these bioreactors is that once the bed is fully fluidized, the pressure drop across the bed remains more or less constant and does not increase with increase in fluid flow rate. Accordingly, the operating cost of the bioreactor also does not change materially with increase in feed flow rate.

Aerobic wastewater treatment in three phase fluidized bed biofilm reactors has been investigated by Narayanan and Biswas [41]. Their study involves a rigorous mathematical modeling and simulation of bioreactor performance and subsequent validation of the simulation results by comparing with elaborate experimental data collected on laboratory scale as well as on pilot plant scale. The deviation between the model results and the experimental data was less than $10 \%$ (which ascertains the accuracy of the software package developed). The simulation package has been developed based on the PFDR approach. The performance equation is thus similar to Eq. (33), except that $D_{L P}$ is to be replaced by $D_{L f}$ (axial dispersion coefficient in fluidized bed which is of higher magnitude than $D_{L P}$ ) and $\epsilon_{P L}$ by $\epsilon_{f L}$. Also, Eq. (26) gets modified to

$$
\mu_{m}(\text { app })=\left(\mu_{m} / Y\right) x_{f} f\left(1-\epsilon_{f}\right) / \epsilon_{f L}
$$

where $\epsilon_{f}=$ total voidage of the fluidized bed (total fractional fluid holdup in the bed)

$\epsilon_{f L}=$ fractional liquid holdup in the bed

The performance equation is solved numerically using a specially developed numerical algorithm, NUMCM. The operating/system parameters associated with three phase fluidized beds such as minimum fluidization velocity of liquid $\left(U_{\operatorname{Lmf} f}\right)$, fractional gas holdup $\left(\epsilon_{f g}\right)$ and fractional liquid holdup $\left(\epsilon_{f L}\right)$ are estimated from selected experimental correlations reported in literature [42-45]. The air that is admitted from the bottom is assumed to execute dispersed flow. The specific case studies conducted are BOD destruction in pharmaceutical wastewater (follows Monod-type kinetics) and dephenolization of coke oven wastewater (follows Haldane-Andrews kinetics). It is reported that more than $85 \%$ BOD destruction is attained in a $3.3 \mathrm{~m}$ column reactor $(\mathrm{D}=0.5 \mathrm{~m})$ at a feed flow rate of $36,000 \mathrm{~L} \mathrm{~h}^{-1}$ and more than $80 \%$ dephenolization of coke oven wastewater in a $6.0 \mathrm{~m}$ column at the same feed flow rate.

Mowla and Ahmadi [46] have reported mathematical analysis (coupled with experimental data) of wastewater treatment in a three phase fluidized biofilm reactor. They have, however, assumed first order kinetics for biodegradation and consequently, could obtain an analytical solution to the performance equation. This, by itself, forms the serious limitation of their work and the results reported can be applied only to those specific cases where first order kinetics could be assumed for bioconversion.

Laboratory studies on fluidized bed bioreactors have been reported by many authors. For example, Gonzalez et al. $[47,48]$ have studied dephenolization of wastewater in a laboratory fluidized column composed of immobilized Pseudomonas cells, while Deckwer et al. [49] report laboratory investigations on microbial mercury removal in a three phase fluidized bed. The results reported by these authors are encouraging. Further investigations on pilot plant scale-up leading to design of industrial bioreactors shall b certainly worthwhile.

Studies on lactic acid production (anaerobic) from dairy waste (cheese whey) and sugar mill effluent (molasses) in a fluidized bed biofilm reactor using Lactobacillus helveticus culture for the former and Enterococcus faecalis culture for the latter have been presented by 
Narayanan $[50,51]$. Cheese whey is first subjected to ultrafiltration to separate all proteins and the lactose content of the permeate is fermented to lactic acid in the biofilm reactor. In the case of molasses, its sucrose content $\left(<150 \mathrm{~g} \mathrm{~L}^{-1}\right)$ is converted to lactic acid in the fluidized bed biofilm reactor. The reactor operates in two phase (liquid-solid) and particulate fluidization is made to occur in the system. Here also, the performance characteristics of the bioreactor have been substantiated both mathematically (through a rigorous software package) and experimentally (through pilot plant tests). Since it is a two phase system,

$$
\epsilon_{f}=\epsilon_{f L}
$$

The minimum fluidization velocity $\left(U_{m f}\right)$ of the feed solution is estimated from Wen and Yu's correlation [52] and a reasonable estimate of $\epsilon_{f L}$ can be obtained from the correlation proposed by Richardson and Zaki [53] or the modified form proposed by Garside and Al-Dibouni [54]. More than $77 \%$ of lactose present in whey and more than $82 \%$ of sucrose in molasses are converted to lactic acid within a bioreactor of diameter $0.5 \mathrm{~m}, L_{f}=3.0 \mathrm{~m}$ and operating at fluid flow rates exceeding $7500 \mathrm{~L} \mathrm{~h}^{-1}$. It is to be noted that lactic acid is the starting material (monomer) for the synthesis of the popular bioplastic, Poly Laevo Lactic Acid (PLLA). The above study thus successfully demonstrates that lactic acid and thereby the PLLA bioplastic can be economically manufactured on commercial scale starting from waste effluents (the cost of raw material being thus practically nil).

Attempts have also been made to propose improved design of fluidized bed biofilm reactors. For example, Narayanan et al. [55] have successfully illustrated utilization of a diverging- converging fluidized bed biofilm reactor for the synthesis of lactic acid from cheese whey and molasses using the microbial cultures mentioned above and have reported that a bioreactor of such a design provides $20-25 \%$ higher conversion of lactose/ sucrose at the same feed flow rate, as compared to a conventional fluidized bed biofilm reactor of cylindrical geometry and of same volume per unit length. At the same time, the overall pressure drop and thereby the operating cost of the bioreactor is increased only marginally. The reactor column is composed of a number of segments, each segment being made up of two cone frustums joined base to base. If $D_{1}$ is the minimum diameter, $D_{2}$ the maximum diameter and $L_{S}$ the length of each segment, then the angle of convergence/divergence $(\theta)$ is predicted by

$$
\tan (\theta)=\left(D_{2}-D_{1}\right) / L_{S}
$$

Narayanan et al. [55] have maintained $\theta$ close to $5^{0}$ $(\tan (\theta)=1 / 12)$ which is the optimum choice. The axial dispersion coefficient $\left(D_{L}\right)$ is observed to be of lower degree in columns of this geometry [56] and that is the principal reason for their augmented performance. The fabrication cost of such bioreactors shall be invariably higher and this is to be compensated against the enhanced performance efficiency provided by them (without sacrificing much on the operating cost).

Performance characteristics of aerobic fluidized bed bioreactors that employ LPO utilization have been analyzed both mathematically and experimentally by Narayanan [57]. Both fluidized bed biofilm reactors and immobilized cell fluidized bed bioreactors have been considered. Due to the use of LPO, they become more or less two phase systems. The results from the numerical algorithm (employed for solving the performance equations) and pilot plant data were observed to agree with less than $\pm 15 \%$ deviation. Aerobic treatment of wastewater from fertilizer plants and pulp and paper industries are the specific cases considered.

\section{Semifluidized bed biofilm reactors for treatment of industrial wastes/effluents}

Semifluidized bed biofilm reactors are relatively newer entries to the field of waste water treatment. Semifluidization technology has distinct advantages over conventional fluidized beds, though they demand higher operating cost.

The operating liquid velocity or flow rate used in semifluidized bed bioreactors is higher than that employed in conventional fluidized bed bioreactors and as a result, these reactors operate at higher capacities. The bed is fully fluidized, but due to the presence of the top restraint (that is fixed at a height $L_{S f}$ meters from the bottom liquid distributor), all those particle-biofilm aggregates that reach this restraint accumulate below it forming a packed bed of height $L_{P}$ there. The rest of the column remains fully fluidized such that the height of the fluidized section $\left(L_{f}\right)$ would be

$$
L_{f}=\left(L_{S f}-L_{P}\right)
$$

If $L_{S}$ is the initial height of the static bed (prior to fluidization), then the ratio $\left(L_{S f} / L_{S}\right)$ is called the bed expansion ratio $(R)$. One of the popular choices is, $R=2.0$. To note that both $L_{P}$ and $L_{f}$ are hydrodynamic parameters and their magnitudes depend on the operating liquid velocity employed. Schematic of a typical three phase semifluidized bed biofilm reactor is shown in Fig. 1.

Studies on aerobic treatment of industrial effluents for BOD removal and biodegradation of $o$-cresol in three phase semifluidized bed bioreactors have been presented by Narayanan and Biswas [58]. The performance of the bioreactor has been simulated mathematically by assuming it to be equivalent to two PFDRs in series, PFDR - 1 


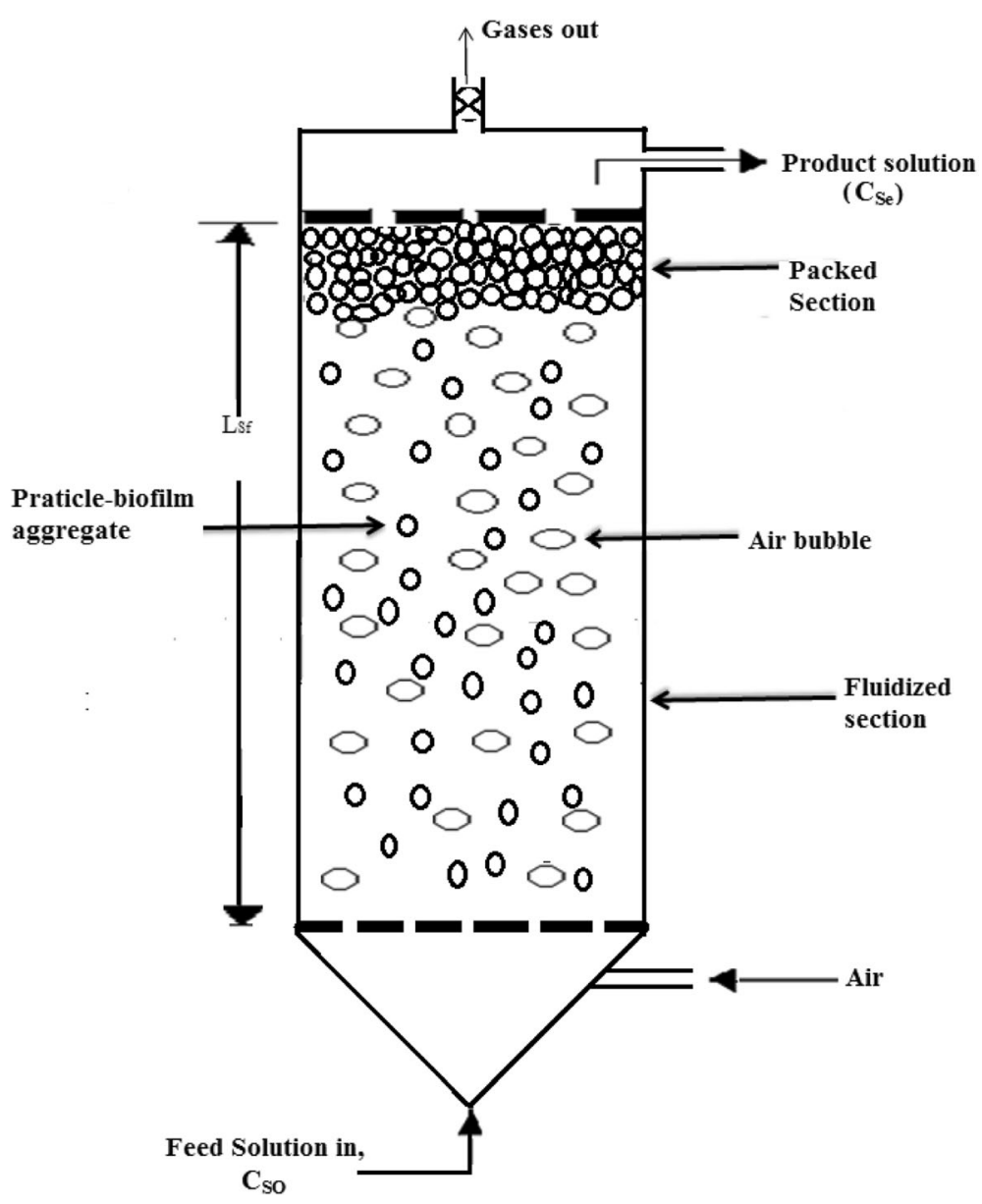

Fig. 1 Schematic of three phase semifluidized bed biofilm reactor

representing the fluidized section and PFDR -2 the packed section of the bioreactor. Accordingly, the performance equation (Eq. (33)) is written separately for the two sections and then solved successively using the numerical algorithm, NUMCM. The results from the software package are well-substantiated using pilot plant test data. Kinetic models considered are Monod-type (for BOD destruction in pulp and paper effluent) and Haldane-Andrews kinetic model for $o$-cresol degradation. The controlling operating parameters such as the minimum semifluidization liquid velocity, height ratio of packed and fluidized sections $\left(L_{P} / L_{f}\right)$, fractional fluid holdups in each section $\left(\epsilon_{f L}, \epsilon_{f g}, \epsilon_{P L}, \epsilon_{P g}\right)$ are estimated from selected experimental correlations available in literature [59-61].

It has been demonstrated that high performance efficiency (more than $80 \%$ BOD destruction/o-cresol removal) is attained within a low reactor volume $\left(\mathrm{D}=0.5 \mathrm{~m}, L_{S f}=\right.$ $1.2 \mathrm{~m}$ ) at high capacities (as high as $82,000 \mathrm{~L} \mathrm{~h}^{-1}$ ). Another interesting feature reported is that in these bioreactors, the fractional substrate conversion $(\alpha)$ increases with increase in feed flow rate. This attractive characteristic (appears anomalous) is due to the fact that as the flow rate of substrate solution increases, more number of particle-biofilm aggregates are transported to the top packed section and consequently, its height $\left(L_{P}\right)$ increases, while that of the fluidized section $\left(L_{f}\right)$ decreases proportionally. A rearrangement of reaction zones thus occurs within the reactor column. Since it has been established $[51,58]$ that the major share of bioconversion is affected in the packed section (where close to plug flow of substrate solution exists), an increase in $L_{P}$ causes increase in fractional conversion of substrate. This, in fact, is an exclusive characteristic exhibited only by the semifluidized bed bioreactors.

Xanthan gum synthesis from dairy waste (cheese whey) using aerobic microbes such as $X$. Campestris in three phase semifluidized bed biofilm reactors has been reported by Narayanan [62]. Based on mathematical analysis (software development) and subsequent experimental verification (pilot plant tests), it is demonstrated that more than $90 \%$ conversion of lactose (present in cheese whey) to Xanthan gum is possible at feed flow rates exceeding $1700 \mathrm{~L} \mathrm{~min}^{-1}$, the reactor volume requirement being quite low $\left(\mathrm{D}=0.5 \mathrm{~m}, L_{S f}=1.0 \mathrm{~m}\right)$. As observed by 
Narayanan and Biswas [58], in this case also, the yield of Xanthan gum was seen to be increasing with increase in reactor capacity.

Commercial synthesis of lactic acid from cheese whey permeate and molasses (sugar mill effluent) in two phase semifluidized bed bioreactors has also been reported [51, 63]. Through mathematical analysis as well as experimental study, the authors have illustrated that more than $80 \%$ lactose conversion and more than $85 \%$ sucrose conversion to lactic acid could be achieved in a bioreactor with $L_{S f}=1.2 \mathrm{~m}$ and $\mathrm{D}=0.5 \mathrm{~m}$, at feed flow rates ranging from 78,000 to 79 , $000 \mathrm{~L} \mathrm{~h}^{-1}$, the fractional substrate conversion attained increasing with increase in substrate flow rate.

Aerobic treatment of distillery and petrochemical wastewater in semifluidized bed biofilm reactor that employs LPO technology has been investigated by Narayanan [64]. The operation of the bioreactor is more steady and it is observed to provide high degree of BOD/COD destruction at high feed flow rates, with reasonably low reactor volume requirement. The operating cost of the reactor is much lower since the use of air compressors has been dispensed with. The observations have been substantiated both mathematically and experimentally.

What has been effectively demonstrated by all of the above reported investigations is that semifluidization technology can be successfully applied to industrial wastewater treatment and also for the recovery of valuable products from industrial effluents. The operating cost of these bioreactors shall be, however, higher since the top packed section would offer additional resistance to substrate flow. The overall economy of industrial adaptation shall thus depend on how far the increased operating cost is compensated by the improved performance characteristics of these bioreactors.

\section{Inverse fluidized bed biofilm reactors for the treatment/handling of industrial wastes / effluents}

Inverse fluidization is often a misleading terminology. These bioreactors employ downflow of feed solution. The particle-biofilm aggregates remain suspended in the descending stream of substrate solution due to the fact that the density of these aggregates (as selected) is lower than that of the substrate solution (see Fig. 2). Polymer beads that are lighter than water, are commonly employed as support particles in these bioreactors. The major advantage of these bioreactors lies in their low operating cost due to the downflow mode of operation, which eliminates the pumping cost of the feed solution.

Experimental studies on aerobic wastewater treatment in laboratory inverse fluidized bed biofilm reactors have been reported by many authors [65-72]. Examples are aerobic treatment of refinery wastewater (for dephenolization) and brewery wastewater [65-68], that of starch

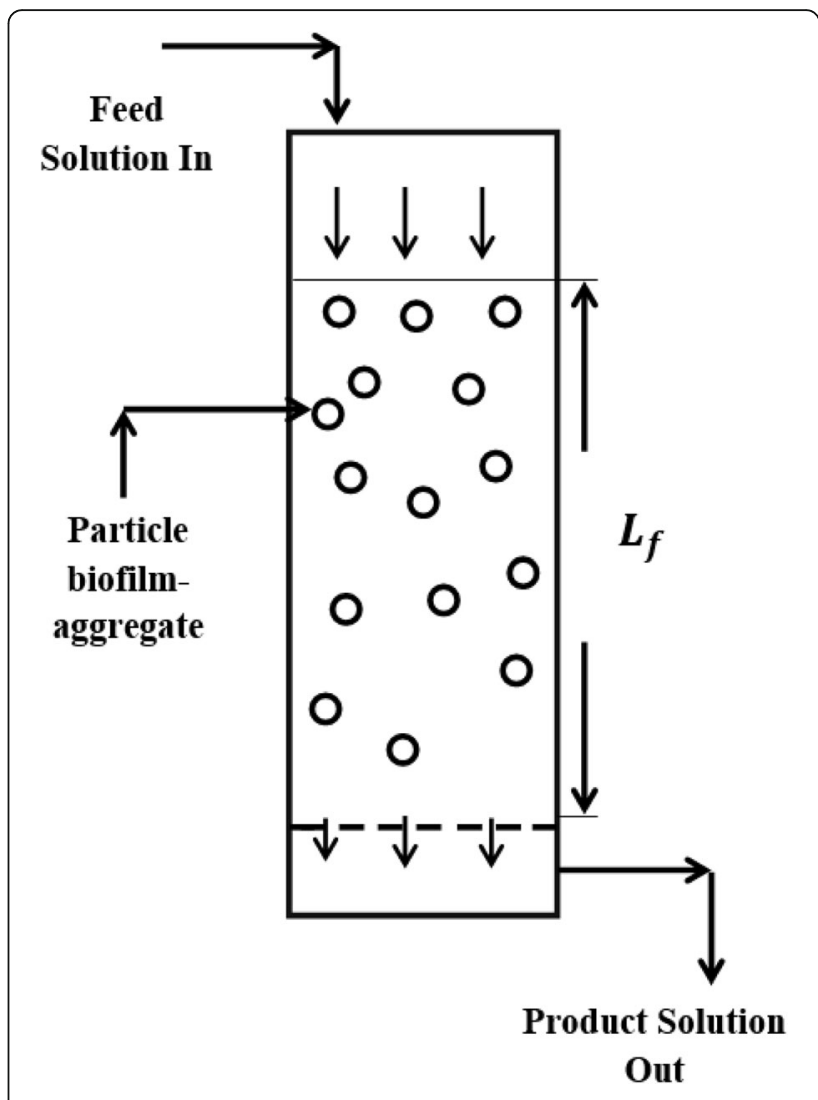

Fig. 2 Schematic of inverse fluidized bed biofilm reactor

wastewater $[69,70]$ and domestic wastewater samples [71]. Experimental data reported by these authors are encouraging, though are on laboratory bench scale. Removal of oil from wastewater in an inverse fluidized bed column composed of aerogel granules has been reported by Quevedo et al. [72]. The oil recovery from contaminated water has been reported to be around $95 \%$.

Mathematical simulation of the performance of two phase inverse fluidized bed biofilm reactors has been attempted by Narayanan et al. [51] and Narayanan and Das [73]. The PFDR approach has been employed here with the developed software tested and verified using lab-scale and pilot plant scale experimental data. The case considered is lactic acid synthesis from cheese whey and molasses and the hydrodynamic parameters associated with have been estimated from available experimental correlations such as those for the computation of minimum inverse fluidization velocity [74-77] and the height of the expanded bed [74, 78-80], the fractional liquid holdup being deduced from a solid balance. The bioreactor has been observed to provide good performance, but relatively lower degree of bioconversion as compared to semifluidized bed bioreactors and the reactor volume requirement is also relatively larger. For example, $76-78 \%$ conversion of lactose/sucrose has been 
reported in a reactor column of diameter $=0.5 \mathrm{~m}$ and expanded bed height $=2.4 \mathrm{~m}$ at a feed flow rate of 59,000 $\mathrm{L} \mathrm{h}^{-1}$. The bioreactor, however, consumes lower operating cost and permits use of larger size support particles (12.5 to $25.4 \mathrm{~mm}$ in size).

More elaborate studies on inverse fluidization technology shall be, no doubt, worthwhile since these systems do have advantages of their own. At high liquid velocities, when hydrodynamic forces generated are of high magnitude, the particle-biofilm aggregates would have a tendency to settle to the bottom of the column and thereby form a packed bed there. In such a situation, the operation of the column shall resemble that of an inverse semifluidized bed. It shall be interesting to study the performance characteristics of such a system and its suitability for bioreactor design. This shall form a fertile area for future research.

\section{DSFF bioreactors for anaerobic waste water treatment}

DSFF bioreactors differ from conventional biofilm reactors discussed above with respect to the fact that these bioreactors do not use any support particles. The biofilm is formed on the inner surface or surfaces of one or more vertical pipes or flow channels through which the feed solution flows down (see Fig. 3). They are relatively simple to construct and maintain and are of low operating cost due to downflow mode of operation.

Experimental studies on anaerobic biological treatment of industrial effluents in DSFF bioreactors have been reported by Henze and Harremoës [81] and Samson et al. [82]. Jovanovic et al. [83] compared the performance of a DSFF bioreactor with that of an upflow anaerobic sludge blanket (UASB) bioreactor, an upflow anaerobic filter (UAF) and a fluidized bed biofilm reactor for the anaerobic degradation of brewery wastewater. They report that both DSFF and UASB bioreactors provide the same degree of COD removal (77\%), while the other two could contribute more than $90 \%$ BOD/COD removal. In a similar experimental investigation, Hall et al. [84] has reported that for the treatment of pharmaceutical wastewater, typical values of BOD removal attained in DSFF, UASB, UAF and fluidized bed biofilm reactor were 60 , 76, 62 and 52\%, respectively, at the same feed flow rate. The UASB bioreactor, however, exhibited operational difficulties since the feed solution had a high concentration of suspended solids, whereas the operation of the DSFF bioreactor had been reportedly smooth and effective. Kennedy and Droste [85] have reported a large amount of experimental data on DSFF bioreactors dealing with anaerobic treatment of waste effluents and have also proposed an approximate mathematical model on the performance of these bioreactors. However, they have assumed $100 \%$ percent back-mixing in the bioreactor (ideal CSTR concept) and have also neglected resistance to substrate transport into the biofilm ( $\eta$ assumed to be equal to unity), though the rate of detachment and attachment of biofilm have been separately accounted for.

An improved and more rigorous mathematical analysis of the performance of DSFF bioreactors has been reported by Narayanan [86], which assumes dispersed flow through the reactor tubes/channels, the degree of axial dispersion being predicted by an appropriately defined axial dispersion coefficient $\left(D_{L}\right)$. The influence of the effectiveness factor $(\eta)$ has also been duly accounted for, the computation of which being performed from Eqs. (28) to (32). Bioconversion involving multiple substrates and complex culture of microbes has been considered. The computed results from the developed mathematical model and pilot plant test data exhibited good agreement (with not more than $\pm 12 \%$ deviation).

Pandey and Narayanan [87] have successfully investigated the use of multichannel DSFF bioreactors for the synthesis of lactic acid from industrial effluents (cheese whey permeate and clarified molasses). Their study also involves mathematical analysis (software development) of bioreactor performance, followed by pilot plant experiments. A typical DSFF bioreactor with a $6.0 \mathrm{~m}$ long flow channel $(25.4 \mathrm{~mm}$ in diameter) reportedly provided around $78 \%$ substrate conversion (lactose/sucrose

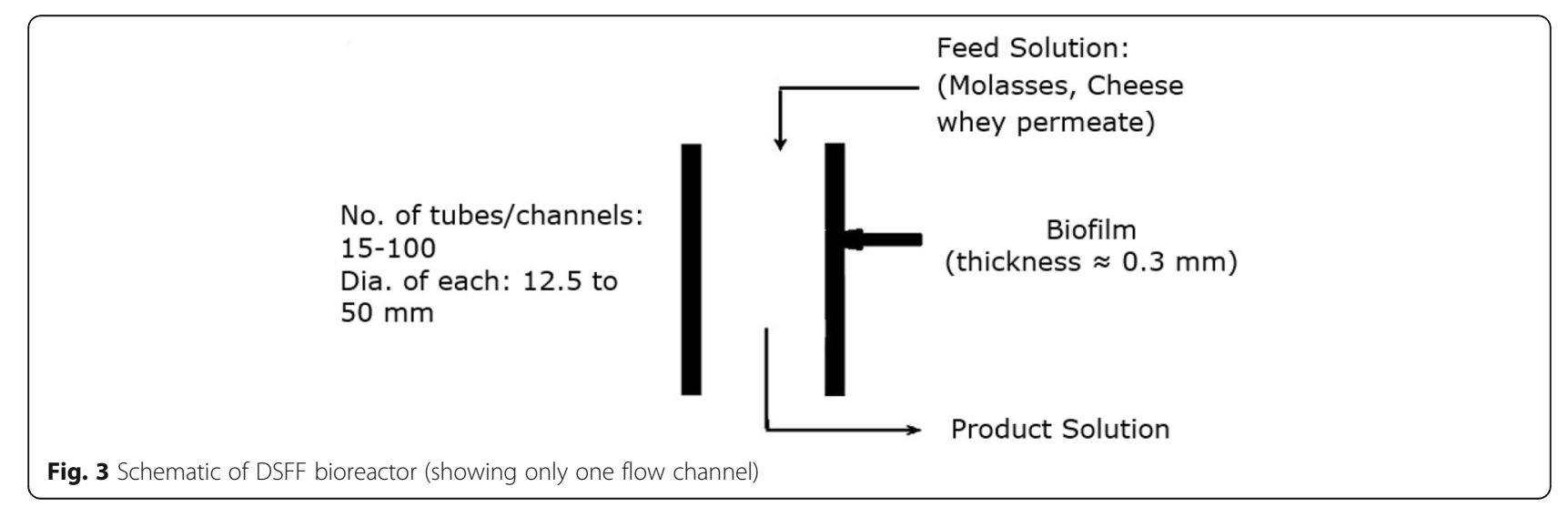


conversion) at a substrate flow rate of $520 \mathrm{~L} \mathrm{~h}^{-1}$. This is when a single flow channel is used. When as many as 30 flow channels are employed (which is very usual), the capacity of the reactor increases to $1560 \mathrm{~L} \mathrm{~h}^{-1}$. As stated earlier, the operating cost of this bioreactor is much lower than that of fluidized bed and semifluidized bed bioreactors.

\section{Anaerobic waste water treatment in UASB bioreactors}

UASB bioreactors entered the industrial scenario relatively late, but quickly established their presence in the arena of anaerobic wastewater treatment. They are sludge bed reactors and they employ sludge granules, which are minute colonies of several classes of microbes that take part in the bioconversion. No support particles are used, the microbial cells collect together and form the sludge granules (the discrete phase). The reactor column consists of a sludge bed at the bottom and a sludge blanket of larger height above it, which is composed of gas bubbles (formed during the anaerobic process) which carry a part of the sludge granules with them as a wake or tail, apart from the substrate solution containing suspended sludge granules. The sludge bed is, in fact, a partially expanded bed. The major share of bioconversion occurs in the sludge blanket.

Industrial adaptation of UASB bioreactors has been fairly rapid, mainly due to its simplicity of construction (it is principally a tall, empty column) and due to the fact that these bioreactors provide large degree of BOD removal (more than 95\%) even with high strength feed stocks and at significantly large capacities. There are around 800 UASB bioreactors that are reportedly operating in full capacity all over the world, out of which around 80 are in India. All of them carry out anaerobic biological treatment of industrial effluents (mainly from breweries, distilleries, food processing and pulp and paper industries). The principal drawback of these bioreactors is their substantially large startup time (quite often amounting to several months) due to the fact that formation of sludge granules (sludge granulation) is a very slow, biological process.

Experimental studies on the performance of UASB bioreactors have been reported by several authors such as those starting from Lettinga et al. [88] to others [89-92]. Satisfactory performance has been reported in all the cases except for its enormously large startup time.

The mechanism of sludge granulation has been investigated by many researchers. A comprehensive survey on the same has been presented by Liu et al. [93]. A number of parameters influence the granulation process such as hydrodynamic forces, electrostatic and Van der Waals forces, surface tensional forces and hydrophobicity of microbial surfaces, chemical forces (hydrogen liaison, formation of ionic pairs) and biochemical forces (cellular membrane fusion, production of extracellular polymers and cell to cell interactions). However, none of the theories based on these parameters could explain the actual mechanism of sludge granule formation satisfactorily, though each of them does influence the process. The overall observation is that microbial sludge granules are syntrophic micro-colonies of different classes of microbes and sludge granulation is an evolutionary, biological process resulting from the natural tendency of different categories of microbes to come together and optimally organize themselves so that the biochemical functions of all of them shall be performed most effectively in the most systematic order. Such a close synergistic relationship among different microbial groups is essential for efficiently breaking down the complex organic wastes. Being a natural, evolutionary process, it is extremely slow and this explains the large startup time demanded by UASB bioreactors. This also explains why sludge granulation occurs only in mixed (complex) culture of microbes.

So far, the tendency to form sludge granules has been observed with anaerobic microbes only (aerobic microbes hardly exhibit this phenomenon). As a result, these bioreactors are restricted to anaerobic treatment of wastes/effluents.

Though the bioreactor is simple in construction and operation, its performance analysis is relatively complex. The simplest approach is to assume the UASB reactor to be equivalent to PFR (sludge bed) and CSTR (sludge blanket) in combination. Such a model, though easy to handle, turns out to be too rudimentary on occasions and fails to predict the reactor performance and its stability reliably. An improved approach is to assume the bioreactor to be equivalent to a PFDR $[94,95]$ with a specified average value of axial dispersion coefficient. However, the performance features of the sludge bed and those of the sludge blanket are not fully comparable (one is a partially expanded bed and the other is equivalent to a three phase fluidized bed) and consequently, it is observed that though this model exhibits good compatibility with industrial data, model results do deviate from real-life data in specific cases. It shall be most innovative therefore to model UASB bioreactor as equivalent to two PFDRs in series [96], PFDR 1 representing the sludge bed and PFDR 2 standing for the sludge blanket. This PFDRs in series model [96] provides fairly accurate predictions on the performances of many industrial UASB bioreactors and could be used with confidence for the installation of new reactor columns and also for modifying the design of existing ones.

Attempts towards diversification of utilization of UASB bioreactors to alternate applications (other than anaerobic digestion of industrial effluents) including 
Table 1 Comparison among bioreactors

\begin{tabular}{|c|c|c|}
\hline Bioreactor & Merits & Limitations \\
\hline Stirred tank & $\begin{array}{l}\text { Simple in construction and operation. Uses suspended growth of } \\
\text { microbes. Suitable for aerobic and anaerobic processes. }\end{array}$ & Restricted to low capacities. \\
\hline $\begin{array}{l}\text { Trickle bed biofilm } \\
\text { reactor }\end{array}$ & $\begin{array}{l}\text { Use of attached growth of microbes. Low operating cost due to down } \\
\text { flow mode of operation. High cell mass concentration in biofilm } \\
\text { promotes rate of bioconversion. }\end{array}$ & $\begin{array}{l}\text { Mainly for aerobic BOD removal. Low capacity due } \\
\text { to low feed flow rate maintained. }\end{array}$ \\
\hline $\begin{array}{l}\text { Moving bed biofilm } \\
\text { reactor (slurry } \\
\text { reactor) }\end{array}$ & $\begin{array}{l}\text { Heterogeneous version of stirred tank. High cell concentration in } \\
\text { biofilm promotes rate of bioconversion }\end{array}$ & $\begin{array}{l}\text { Capacity wise inferior to column reactors. Biofilm } \\
\text { could get disturbed due to high rate of agitation. }\end{array}$ \\
\hline $\begin{array}{l}\text { Fluidized bed } \\
\text { biofilm reactor }\end{array}$ & $\begin{array}{l}\text { Operates at high capacities, provides high degree of bioconversion. } \\
\text { Once fully fluidized, pressured drop across the bed remains constant } \\
\text { and does not increase with increase in feed flow rate. Degree of } \\
\text { bioconversion increases with increase in feed flow rate due to bed } \\
\text { expansion }\end{array}$ & $\begin{array}{l}\text { Entrainment loss of particle-biofilm aggregates pos- } \\
\text { sible. Operating cost higher than trickle bed (packed } \\
\text { bed). }\end{array}$ \\
\hline $\begin{array}{l}\text { Semifluidized bed } \\
\text { biofilm reactor }\end{array}$ & $\begin{array}{l}\text { Higher degree of bioconversion (than fluidized beds) at higher } \\
\text { capacities and low reactor volume requirement. Degree of } \\
\text { bioconversion increases with increase in feed flow rate, even if reactor } \\
\text { volume is kept constant. }\end{array}$ & $\begin{array}{l}\text { Higher operating cost than fluidized beds. } \\
\text { Continuous, circulating mode of operation not } \\
\text { possible. }\end{array}$ \\
\hline $\begin{array}{l}\text { Inverse fluidized } \\
\text { biofilm reactor }\end{array}$ & $\begin{array}{l}\text { Low operating cost due to down flow mode of operation. Larger size } \\
\text { particles could be used. Reasonably large degree of bioconversion. }\end{array}$ & $\begin{array}{l}\text { Lower capacity than fluidized /semi-fluidized bed. } \\
\text { Larger reactor volume requirement }\end{array}$ \\
\hline DSFF bioreactor & $\begin{array}{l}\text { Simple in construction and operation. No support particles required. } \\
\text { Low operating cost due to downflow mode of operation. Multiple } \\
\text { tubes / columns could be used to increase capacity. }\end{array}$ & $\begin{array}{l}\text { Presently restricted to anaerobic operation. Large } \\
\text { reactor volume requirement at high capacities. }\end{array}$ \\
\hline UASB reactor & $\begin{array}{l}\text { Simple in construction. No support particles used. Provides substantially } \\
\text { high degree of bioconversion at distinctly high capacities and even } \\
\text { with high strength feedstock. }\end{array}$ & $\begin{array}{l}\text { Restricted to anaerobic processes, employing } \\
\text { complex culture of microbes. Enormously large } \\
\text { startup time. }\end{array}$ \\
\hline
\end{tabular}

hydrogen production shall certainly be worthwhile and this would form a potential area for future research.

An interesting modification of UASB reactor is the expanded granular sludge bed (EGSB) reactor. In these reactors, the feed solution is admitted from the bottom at a larger velocity and as a result, the sludge granules remain partially fluidized in the upflowing liquid stream. The granules remain suspended in the ascending liquid and thus form an expanded or fluidized bed, which permits more uniform dispersion of sludge granules. At the top of the reactor, there is a chamber of larger cross-section, which acts as a gasliquid-solid separator. The biogas goes out through the top outlet (through the gas cap) and the treated liquid effluent is discharged through a side outlet. Due to the increase in cross-sectional area, liquid velocity drops and the sludge granules settle down, back to the reaction zone (expanded bed). The EGSB design is particularly suitable for handling medium strength feedstock or those containing inert or poorly biodegradable particles that could otherwise clog the sludge bed of an UASB reactor. A rigorous computeraided analysis and simulation of the performance of EGSB reactors has been reported by Narayanan and Narayan [97]. Here also, the analysis is based on PFDR approach. The results from the software package have been adequately verified by comparing with pilot plant test data.

\section{Comparison among bioreactors}

A broad comparison among the different bioreactors described above is presented in Table 1. This table summarizes the specific merits as well as limitations of each bioreactor.

\section{Conclusions}

Wastewater treatment processes have come a long way and many newer and novel approaches have been developed in this connection during the recent years. Coupling of wastewater treatment with waste utilization is a very attractive proposition and the different processes/ equipment (bioreactors) developed for the same are surveyed in this paper. It is observed that different types of bioreactors with attractive characteristics have been developed by various researchers and their industrial adaptation must be strongly recommended. It is also observed that clubbing of different technologies (such as LPO technology) with conventional wastewater treatment processes would also be highly promising and attempts in this connection must also be very much encouraged.

\section{Nomenclature}

a specific interfacial area for mass transfer, $\mathrm{m}^{2} \mathrm{~m}^{-3}$ $C_{A}$ concentration of unionized acetic acid in solution, $\mathrm{g} \mathrm{L}^{-1}$ $C_{N}$ concentration of hydrogen peroxide, $\mathrm{M}$ $C_{N 0}$ concentration of ammonia in solution, $\mathrm{g} \mathrm{L}^{-1}$ 
$C_{S}$ substrate concentration in liquid, $\mathrm{g} \mathrm{L}^{-1}$ or $\mathrm{M}$

$C_{S e}$ substrate concentration in product solution, $\mathrm{g} \mathrm{L}^{-1}$ or $\mathrm{M}$

$C_{S O}$ substrate concentration in feed solution, $\mathrm{g} \mathrm{L}^{-1}$ or $\mathrm{M}$

$C_{S P}$ substrate concentration at biofilm-liquid interface, $\mathrm{g} \mathrm{L}^{-1}$ or $\mathrm{M}$

$C_{g}$ concentration of carbon dioxide in gas space, $\mathrm{M}$

$C_{g L}$ concentration of carbon dioxide in solution, $\mathrm{g} \mathrm{L}^{-1}$

$d_{P}$ diameter of support particle, $\mathrm{m}$

$d_{P m}$ diameter of particle-biofilm aggregate, $\mathrm{m}$

$D$ diameter of bioreactor column, $\mathrm{m}$

$D_{e}$ effective diffusivity of substrate into biofilm, $\mathrm{m}^{2} \mathrm{~s}^{-1}$

$D_{L}$ axial dispersion coefficient, $\mathrm{m}^{2} \mathrm{~s}^{-1}$

$D_{L P}$ axial dispersion coefficient for packed section, $\mathrm{m}^{2} \mathrm{~s}^{-1}$

$D_{L f}$ axial dispersion coefficient for fluidized section, $\mathrm{m}^{2} \mathrm{~s}^{-1}$

$D_{1}, D_{2}$ minimumand maximum diameter respectively of

diverging-converging column, $\mathrm{m}$

$f$ volume fraction of biofilm in particle-biofilm aggregate, $\mathrm{m}^{3} \mathrm{~m}^{-3}$

$\mathrm{He}$ Henry's law constant, $\mathrm{M} \mathrm{kPa}^{-1}$

$k_{d}$ endogenous decay coefficient, $\mathrm{s}^{-1}$

$k_{L}$ liquid phase mass transfer coefficient, $\mathrm{m} \mathrm{s}^{-1}$

$K_{1}$ equilibrium constant for carbon dioxide dissolution, $\mathrm{M}$

$K_{a}$ ionization constant of acetic acid, $\mathrm{M}$

$K_{C}$ Contois kinetic constant, dimensionless

$K_{N} \mathrm{LPO}$ utilization coefficient, $\mathrm{g} \mathrm{L}^{-1}$ or $\mathrm{M}$

$K_{S}$ kinetic constant, $\mathrm{g} \mathrm{L}^{-1}$ or $\mathrm{M}$

$K_{S i}$ substrate inhibition coefficient, $\mathrm{g} \mathrm{L}^{-1}$ or $\mathrm{M}$

$L^{*}$ characteristic dimension of particle-biofilm aggregate, $\mathrm{m}$

$L_{f}$ height of fluidized bed, $\mathrm{m}$

$L_{P}$ height of packed bed/section, $\mathrm{m}$

$L_{S}$ height of initial static bed; segment length of diverging-converging column, $\mathrm{m}$

$L_{S f}$ total height of semifluidized bed, $\mathrm{m}$

$p_{C}$ partial pressure of carbon dioxide in gas space, $\mathrm{kPa}$

$Q$ rate of production of biogas, $\mathrm{m}^{3} \mathrm{~s}^{-1}$

$Q_{o}$ volume flow rate of substrate (feed) solution, $\mathrm{m}^{3} \mathrm{~s}^{-1}$

$\left(-r_{S}\right)($ int $)$ intrinsic rate of bioconversion, $\mathrm{g} \mathrm{L}^{-1} \mathrm{~s}^{-1}$ or $\mathrm{M} \mathrm{s}^{-1}$

$R$ bed expansion ratio, dimensionless

$R_{C}$ net rate of production of carbon dioxide in solution, $\mathrm{m}^{3} \mathrm{~s}^{-1}$

$U$ (sup) superficial velocity of substrate solution through the reactor column, $\mathrm{m} \mathrm{s}^{-1}$

$U_{L}$ actual velocity of liquid, $\mathrm{m} \mathrm{s}^{-1}$

$U_{m f}$ minimum fluidization velocity of liquid in liquid solid fluidized bed, $\mathrm{m} \mathrm{s}^{-1}$

$U_{\text {Lmf }}$ minimum fluidization velocity of liquid in three phase fluidized bed, $\mathrm{m} \mathrm{s}^{-1}$

$V$ reactor volume, $\mathrm{m}^{3}$

$x_{f}$ biomass (cell mass) concentration in biofilm, $\mathrm{g} \mathrm{L}^{-1}$

$x_{e}$ biomass (cell mass) concentration in product solution, $\mathrm{g} \mathrm{L}^{-1}$

$Y$ overall yield coefficient for cell mass production, $\mathrm{mg} \mathrm{mg}^{-1}$

$Y_{C}$ yield coefficient for carbon dioxide production, $\mathrm{mol} \mathrm{mol}^{-1}$
$Y_{e}$ trueyield coefficient for cell mass production, $\mathrm{mg} \mathrm{mg}^{-1}$

$Y_{m}$ yield coefficient for methane production, $\mathrm{mol} \mathrm{mol}^{-1}$

$\alpha$ fractional conversion of substrate, dimensionless

$\beta$ parameter defined in Eq. (23), dimensionless

$\delta$ biofilm thickness, $\mathrm{m}$

$\varepsilon_{f}$ total voidage offluidized bed, dimensionless

$\varepsilon_{f g}$ fractional gas holdup in fluidized bed, dimensionless

$\varepsilon_{\mathcal{L}}$ fractional liquid holdup in fluidized bed, dimensionless

$\varepsilon_{P}$ total voidage of packed bed/section, dimensionless

$\varepsilon_{P g}$ fractional gas holdup in packed bed/section,

dimensionless

$\varepsilon_{P L}$ fractional liquid holdup in packed bed/section, dimensionless

$\eta$ effectiveness factor, dimensionless

$\theta$ angle of convergence/divergence, degrees

$\mu_{L}$ liquid viscosity, $\mathrm{kg} \mathrm{m}^{-1} \mathrm{~s}^{-1}$

$\mu_{m}$ maximum specific growth rate, $\mathrm{s}^{-1}$

$\rho_{g}$ molar density ofbiogas, $\mathrm{mol} \mathrm{m}^{-3}$

$\rho_{L}$ liquid density, $\mathrm{kg} \mathrm{m}^{-3}$

$\rho_{m}$ density of microbial solution, $\mathrm{kg} \mathrm{m}^{-3}$

$\rho_{S}$ density of support particle, $\mathrm{kg} \mathrm{m}^{-3}$

$\tau$ space time, $\mathrm{s}$

$\varnothing$ Thiele-type modulus, dimensionless

\section{Acknowledgements}

The authors express their hearty vote of thanks to all of his fellow members of IRG (International Research Group), to a number of consultancy firms of India and abroad and above all, to the young students of first author (Amritha Ajeej, Subrata Biswas, Shrijita Das and Aditi Pandey) for their assistances during the successful execution of many of the projects cited in this paper.

Authors' contributions

The manuscript has been read and approved by both the authors.

\section{Authors' information}

Prof. (Dr.) C. M. Narayanan is former Professor of Chemical Engineering, National Institute of Technology, Durgapur, India. After 40 (forty) years of service, he retired from NIT in 2016. He received B. Tech in Chemical Engineering from Banaras Hindu University, M.E. from Indian Institute of Science, Bangalore and PhD from Indian Institute of Technology, Kharagpur. $\mathrm{He}$ is the author of 105 research papers in international journals. He has also authored SEVEN books on Chemical Engineering and Bioprocess

Engineering, including a Chapter in the Handbook of Food Bioengineering. He has been conferred with Bharat Jyoti Award and Most Eminent Engineering Personality Award for his outstanding contribution to chemical and biochemical engineering education and research, particularly in the areas of Computer Aided Design and Software Development and Bioprocess Engineering. Represented India in many world conferences, had been Visiting Scientist/Faculty to many institutions of Asia and Europe, is member of editorial board of many prestigious international journals. Presently works as a freelance CAD (Software) consultant and Educational Advisor to five engineering institutions of India. Visit him at: www.profcmn.com. Dr. Vikas Narayan received his B. Tech in Chemical Engineering from Lakshminarayan Institute of Technology, Nagpur, India, M.S. in Bioprocess Engineering from Indian Institute of Technology, Madras and PhD in Chemical Engineering from Denmark Technical University, Denmark. He has served as Project Engineer at GE (Energy), Bangalore and as Research Engineer at Siemens Information Systems, Bangalore. Presently, he is serving as Senior Research Engineer at Saudi Basic Industries Corporation (SABIC), Bangalore. He has published five research papers in international journals and five in conference proceedings. 


\section{Funding}

No specific funding has been received for this study from any particular agency.

\section{Availability of data and materials}

Not applicable

\section{Competing interests}

The authors declare that there are no conflicts of interest. The authors also certify that there are no ethical issues involved.

\section{Author details}

${ }^{1}$ National Institute of Technology, Durgapur 713209, India. ${ }^{2}$ Denmark Technical University, 2800 Kongens Lyngby, Denmark.

Received: 31 January 2019 Accepted: 12 November 2019 Published online: 11 December 2019

\section{References}

1. Rao KR, Subrahmanyam N. Process variations in activated sludge process a review. Ind Chem Engr. 2004;46:48-55.

2. Metcalf \& Eddy Inc. Wastewater engineering: treatment, disposal and reuse. 2nd ed. New Delhi: Tata McGraw-Hill; 1979.

3. Narayanan CM. Biotechnology and bioprocess engineering. New Delhi: Galgotia Publishers; 2011.

4. Narayanan CM. Case studies on biological wastewater treatment and software development. In: Indian Chemical Engineering Congress (CHEMCON-2003). Bhubaneswar; 2003.

5. Zabot GL, Mecca J, Mesomo M, Silva MF, Pra VD, Oliveira D, et al. Hybrid modeling of xanthan gum bioproduction in batch bioreactor. Bioprocess Biosyst Eng. 2011;34:975-86.

6. Vikas N, Vinod JK, Kumar S. Cultivation of recombinant E.coli using LPO strategy. In: Indian Chemical Engineering Congress (CHEMCON-2005). New Delhi; 2005

7. Smith R. USEPA report: 170-40-05-70. Washington, DC: US Environmental Protection Agency; 1970

8. Narayanan CM. Energy conservation employing membrane-based technology. Chem Ind Digest. 1993;6:133-6.

9. Thakura R, Chakraborty S, Pal P. Treating complex industrial waste water in a new membrane - integrated closed loop system for recovery and reuse. Clean Techn Environ Policy. 2015;17:2299-310.

10. Narayanan CM. Production of phosphate rich biofertiliser using vermicompost and anaerobic digester sludge - a case study. Adv Chem Eng Sci. 2012;2:187-91.

11. Sekhar DMR, Aery NC. PROM manual. Udaipur: Himanshu Publishers; 2005.

12. Bailey JE, Ollis DF. Biochemical engineering fundamentals. 2nd ed. Singapore: McGraw Hill; 1986

13. Momoh OLY, Nwaogazie LI. Effect of waste paper on biogas production from co-digestion of cow dung and water hyacinth in batch reactors. J Appl Sci Environ Manage. 2008;12:95-8.

14. Samson R, LeDuy A. Improved performance of anaerobic digestion of Spirulina maxima algal biomass by addition of carbon-rich wastes. Biotechnol Lett. 1983:5:677-82.

15. Yen HW, Brune DE. Anaerobic co-digestion of algal sludge and waste paper to produce methane. Bioresour Technol. 2007;98:130-4.

16. Costa JC, Goncalves PR, Nobrel A, Alves MM. Biomethanation potential of macroalgae Ulva spp. and Gracilaria spp. and in co-digestion with waste activated sludge. Bioresour Technol. 2012;114:320-6.

17. Yuan X, Wang M, Park C, Sahu AK, Ergas SJ. Microalgae growth using highstrength wastewater followed by anaerobic co-digestion. Water Environ Res. 2012;84:396-404.

18. Krustok I, Nehrenheim E, Odlare M. Cultivation of microalgae for potential heavy metal reduction in a wastewater treatment plant. In: International Conference on Applied Energy. Suzhou; 2012.

19. Olsson J, Feng XM, Ascue J, Gentili FG, Shabiimam MA, Nehrenheim E, et al. Co-digestion of cultivated microalgae and sewage sludge from municipal waste water treatment. Bioresour Technol. 2014;171:203-10.

20. Ajeej A, Thanikal JV, Narayanan CM, Kumar RS. An overview of bio augmentation of methane by anaerobic co-digestion of municipal sludge along with microalgae and waste paper. Renew Sust Energ Rev. 2015;50: 270-6.
21. Ajeej A, Thanikal JV, Narayanan CM, Yazidi H. Studies on the influence of the characteristics of substrates in biogas production. Int J Curr Res. 2016;8:39795-9.

22. Ajeej A, Thanikal JV, Narayanan CM. Studies on production of biogas by codigestion of sewage sludge, wastepaper and waste grown algae. J Mod Chem Chem Technol. 2016;7:74-81.

23. Graef SP, Andrews JF. Mathematical modeling and control of anaerobic digestion. Chem Eng Prog S Ser. 1974;70:101-7.

24. Rai GD. Nonconventional energy sources. New Delhi: Khanna Publishers; 1996.

25. Rahman $\mathbf{M H}$, Al-Muyeed A. Solid and hazardous waste management. Dhaka: Center for Water Supply and Waste Management; 2010.

26. Narayanan CM, Bhattacharya BC. Computer aided analysis and optimization of biogas enrichment process. J Energ Heat Mass Transf. 1990;12:17-24.

27. Rao MG, Sittig M. Dryden's outlines of chemical technology. 3rd ed. New Delhi: East-West Press; 1997

28. Rajvaidya AS. Pre-combustion desulfurisation of gaseous fuels. In: All India Seminar on Recent Trends in Automotive Fuels. Nagpur; 2002.

29. Gottifredi JC, Gonzo EE. Approximate expression for the effectiveness factor estimation and a simple numerical method for concentration profile calculation in porous catalyst. Chem Eng J. 2005;109:83-7.

30. Eckenfelder WW. Water quality engineering for practicing engineers. New York: Barnes and Noble; 1970.

31. Narayanan CM. Trickle bed reactors for biological wastewater treatment multiparameter simulation and software development. In: International Conference on Advances in Industrial Wastewater Treatment. New Delhi: Allied Publishers; 2005

32. Carberry JJ. Chemical and catalytic reaction engineering. New York: McGraw Hill; 1976.

33. Saez AE, Carbonell RG. Hydrodynamic parameters for gas-liquid cocurrent flow in packed beds. AICHE J. 1985;31:52-62.

34. Specchia $\vee$, Baldi G. Pressure drop and liquid holdup for two phase concurrent flow in packed beds. Chem Eng Sci. 1977;32:515-23.

35. Iliuta I, Thyrion FC. Flow regimes, liquid holdups and two-phase pressure drop for two-phase cocurrent downflow and upflow through packed beds: air/Newtonian and non-Newtonian liquid systems. Chem Eng Sci. 1997:52: 4045-53.

36. Kawatra P, Panyaram S, Wilhite BA. Hydrodynamics in a pilot-scale cocurrent trickle-bed reactor at low gas velocities. AICHE J. 2018;64:2560-9.

37. Chen S, Sun DZ, Chung JS. Simultaneous removal of COD and ammonium from landfill leachate using an anaerobic-aerobic moving-bed biofilm reactor system. Waste Manag. 2008:28:339-46.

38. Anandkumar J, Yadu A, Sahariah BP. Studies on biological degradation of 4bromophenol using anaerobic, anoxic and aerobic bioreactors. J Mod Chem Chem Technol. 2016;7:37-41

39. Sahariah BP, Anandkumar J, Chakraborty S. Treatment of coke oven wastewater in an anaerobic-anoxic-aerobic moving bed bioreactor system. Desalin Water Treat. 2016:57:14396-402.

40. Shieh WK, Keenan JD. Fluidized bed biofilm reactor for wastewater treatment. Bioproducts. Advances in Biochemical Engineering/ Biotechnology, vol. 33. Berlin: Springer; 1986. p. 131-69.

41. Narayanan CM, Biswas S. Computer aided design and analysis of three phase fluidized bed biofilm reactors for waste water treatment. Asian J Biochem Pharm Res. 2015;5:224-49.

42. Fortin Y. Réacteurs à lit fluidisé triphasique: caractéristiques hydrodynamiques et mélange des particules solides [Ph.D. Thesis]. Nancy: Institut National Polytechnique de Lorraine; 1984. [in French]

43. Dakshinamurty $P$, Subrahmanyam $V$, Rao JN. Bed porosities in gas-liquid fluidization. Ind Eng Chem Proc Dd. 1972;11:318-9.

44. Kim SD, Baker CGI, Bergougnou MA. Phase holdup characteristics of three phase fluidized beds. Can J of Chem Eng. 1975;53:134-9.

45. Jena HM, Sahoo BK, Roy GK, Meikap BC. Statistical analysis of the phase holdup characteristics of a gas-liquid-solid fluidized bed. Can J Chem Eng. 2009:87:1-10.

46. Mowla D, Ahmadi A. Theoretical and experimental investigation of biodegradation of hydrocarbon polluted water in a three phase fluidizedbed bioreactor with PVC biofilm support. Biochem Eng J. 2007;36:147-56.

47. Gonzalez G, Herrera MG, Garcia MT, Pena MM. Biodegradation of phenol in a continuous process: comparative study of stirred tank and fluidized-bed bioreactors. Bioresour Technol. 2001:76:245-51.

48. Gonzalez G, Herrera G, Garcia MT, Pena M. Biodegradation of phenolic industrial wastewater in a fluidized bed bioreactor with immobilized cells of Pseudomonas putida. Bioresour Technol. 2001;80:137-42. 
49. Deckwer WD, Becker FU, Ledakowicz S, Wagner-Dobler I. Microbial removal of ionic mercury in a three-phase fluidized bed reactor. Environ Sci Technol. 2004;38:1858-65

50. Narayanan CM. Case studies on synthesis of PLLA bioplastic starting from food and agricultural wastes. Int J Chem Eng Proc. 2015;1:1-13.

51. Narayanan CM, Das S, Pandey A. Food waste utilization: green technologies for manufacture of valuable products from food wastes and agricultural wastes. In: Grumezescu AM, Holban AM, editors. Food bioconversion. Handbook of food bioengineering - Volume 2. London: Academic Press; 2017. p. 1-54.

52. Wen $\mathrm{CY}, \mathrm{Yu} \mathrm{YH}$. A generalized method for predicting the minimum fluidization velocity. AICHE J. 1966;12:610-2.

53. Richardson JF, Zaki WN. Sedimentation and fluidization. Part I. Trans Inst Chem Eng. 1954;32:35-53.

54. Garside J, Al-Dibouni MR. Velocity-voidage relationships for fluidization and sedimentation in solid-liquid systems. Ind Eng Chem Proc Dd. 1977;16:206-14.

55. Narayanan CM, Basak A, Saha A, Jha S. Studies on performance characteristics of diverging - converging fluidized bed biofilm reactor with special reference to lactic acid synthesis from molasses and cheese whey. Int Rev Chem Eng. 2014;6:142-52.

56. Narayanan CM. Process analysis, simulation and software development - a few applications. In: International Conference on Recent Advances in Chemical Engineering. Kochi; 2011.

57. Narayanan CM. Modeling and simulation of fluidized bed bioreactors with liquid phase oxygen utilization. Int J Trans Phenom. 2009;11:127-32.

58. Narayanan CM, Biswas S. Studies on waste water treatment in three phase semifluidized bed bioreactors - computer aided analysis and software development. J Mod Chem Chem Technol. 2016;7:1-21.

59. Jena HM. Hydrodynamics of gas-liquid-solid fluidized and semi-fluidized beds [Ph.D. dissertation]. National Institute of Technology: Rourkela; 2009.

60. Chern SH, Fan LS, Muroyama K. Hydrodynamics of cocurrent gas-liquid-solid semifluidization with a liquid as the continuous phase. AICHE J. 1984;30: 288-94

61. Saberian-Broudjenni M, Wild G, Charpentier JC, Fortin Y, Euzen JP, Patoux R. Contribution to the hydrodynamic study of gas-liquid-solid fluidized bed reactors. Int Chem Eng. 1987;27:423-40.

62. Narayanan CM. Studies on computer-aided design and analysis of three-phase semifluidized bed bioreactors. Chem Prod Process Model. 2015;10:55-70.

63. Narayanan CM, Das S. Studies on synthesis of lactic acid from molasses and cheese whey in semifluidized bed biofilm reactors. Int J Environ Waste Manag. 2017;19:1-20.

64. Narayanan CM. Performance analysis of semi fluidized bed biofilm reactors with liquid phase oxygen (LPO) utilization. In: 14th International Conference on Fluidization - From Fundamentals to Products. Noordwijkerhout; 2013.

65. Sokol W. Treatment of refinery wastewater in a three-phase fluidised bed bioreactor with a low density biomass support. Biochem Eng J. 2003;15:1-10.

66. Sokol W, Korpal W. Phenolic wastewater treatment in a three-phase fluidised bed bioreactor containing low density particles. J Chem Technol Biot. 2005;80:884-91

67. Sokol W, Korpal W. Aerobic treatment of wastewaters in the inverse fluidised bed biofilm reactor. Chem Eng J. 2006;118:199-205.

68. Sokół W, Woldeyes B. Evaluation of the inverse fluidized bed biological reactor for treating high-strength industrial wastewaters. Adv Chem Eng Sci. 2011;1:239-44.

69. Rajasimman M, Karthikeyan C. Aerobic digestion of starch wastewater in a fluidized bed bioreactor with low density biomass support. J Hazard Mater. 2007;143:82-6.

70. Rajasimman $\mathrm{M}$, Karthikeyan C. Optimization studies in an inverse fluidized bed bioreactor for starch wastewater treatment. Int J Environ Res. 2009;3: 569-74.

71. Haribabu K, Sivasubramanian V. Biodegradation of organic content in wastewater in fluidized bed bioreactor using low-density biosupport. Desalin Water Treat. 2016:57:4322-7.

72. Quevedo JA, Patel G, Pfeffer R. Removal of oil from water by inverse fluidization of aerogels. Ind Eng Chem Res. 2009:48:191-201.

73. Narayanan CM, Das S. Computer aided design and performance analysis of inverse fluidized bed biofilm reactors with special reference to bioplastic synthesis. Adv Chem Eng Sci. 2016;6:130-9.

74. Ulaganathan N, Krishnaiah K. Hydrodynamic characteristics of two-phase inverse fluidized bed. Bioprocess Eng. 1996;15:159-64.
75. Cho YJ, Park HY, Kim SW, Kang Y, Kim SD. Heat transfer and hydrodynamics in two- and three-phase inverse fluidized beds. Ind Eng Chem Res. 2002:41: 2058-63.

76. Lakshmi ACV, Balamurugan M, Sivakumar M, Samuel TN, Velan M. Minimum fluidization velocity and friction factor in a liquid-solid inverse fluidized bed reactor. Bioprocess Eng. 2000;22:461-6.

77. Banerjee J, Basu JK, Ganguly UP. Some studies on the hydrodynamics of reverse fluidization velocities. Ind Chem Engr. 1999;41:35-8.

78. Fan LS, Muroyama K, Chern SH. Hydrodynamic characteristics of inverse fluidization in liquid-solid and gas-liquid-solid systems. Chem Eng J Bioch Eng. 1982;24:143-50.

79. Nikolov I, Karamanev D, Zhelyazkov T. Extended study on the hydrodynamics of a cold model of the inverse fluidized bed bioreactor. Biotech Biotechnol Equip. 1994;8:75-9.

80. Bendict RJF, Kumaresan C, Velan M. Bed expansion and pressure drop studies in a liquid-solid inverse fluidised bed reactor. Bioprocess Eng. 1998; 19:137-42.

81. Henze M, Harremoës P. Anaerobic treatment of wastewater in fixed film reactors - a literature review. Water Sci Technol. 1983;15:1-101.

82. Samson R, van den Berg L, Kennedy KJ. Mixing characteristics and startup of anaerobic downflow stationary fixed film (DSFF) reactors. Biotechnol Bioeng 1985:27:10-9.

83. Jovanovic M, Murphy KL, Hall ER. Parallel evaluation of high rate anaerobic treatment processes: retention time and concentration effects. In: EWPCA Conference on Anaerobic Treatment: A Grown-up Technology. Amsterdam; 1986.

84. Hall ER, Jovanovic M, Pejic M. Pilot studies of methane production in fixed film and sludge blanket anaerobic reactors. In: Fourth Bioenergy Research and Development Seminar. Winnipeg; 1982.

85. Kennedy KJ, Droste RL. Anaerobic wastewater treatment in downflow stationary fixed film reactors. Water Sci Technol. 1991;24:157-77.

86. Narayanan CM. Performance analysis of anaerobic downflow stationary fixed film (DSFF) bioreactors and software development. Int J Chem React Eng. 2009;7:A61

87. Pandey A, Narayanan CM. Studies on synthesis of lactic acid from agricultural and food wastes in downflow stationary fixed film (DSFF) bioreactors. Int J Trans Phenom. 2017:14:241-54.

88. Lettinga $G$, Roersma R, Grin P. Anaerobic treatment of raw domestic sewage at ambient temperatures using a granular bed UASB reactor. Biotechnol Bioeng. 1983;25:1701-23.

89. Seghezzo L, Zeeman G, van Lier JB, Hamelers HVM, Lettinga G. A review: the anaerobic treatment of sewage in UASB and EGSB reactors. Bioresour Technol. 1998;65:175-90.

90. Sponza DT. Anaerobic granule formation and tetrachloroethylene (TCE) removal in an upflow anaerobic sludge blanket (UASB) reactor. Enzyme Microb Tech. 2001;29:417-27.

91. Veeresh GS, Kumar P, Mehrotra I. Treatment of phenol and cresols in upflow anaerobic sludge blanket (UASB) process: a review. Water Res. 2005:39:154-70.

92. Riyas PS, Sajeena BB, Haridas A. Design and analysis of a UASB for Sabarimala Sannidhanam 5 MLD sewage treatment plant. In: International Conference on Advances in Chemical Engineering and Technology. New Delhi: Reed Elsevier India (P) limited; 2014.

93. Liu Y, Xu HL, Yang SF, Tay JH. Mechanisms and models for anaerobic granulation in upflow anaerobic sludge blanket reactor. Water Res. 2003;37: $661-73$

94. Kalyuzhnyi SV, Fedorovieh W, Lens P. Dispersed plug flow model for upflow anaerobic sludge bed reactors with focus on granular sludge dynamics. J Ind Microbiol Biot. 2006;33:221-37.

95. Narayanan CM, Narayan V. Multiparameter models for performance analysis of UASB reactors. J Chem Technol Biot. 2008;83:1170-6.

96. Narayanan CM, Samui E, Chatterjee A, Das S. A parametric study of performance characteristics of upflow anaerobic sludge blanket bioreactors. Res J Chem Sci. 2012;2:12-20.

97. Narayanan CM, Narayan $\mathrm{V}$. Software package for process simulation and computer aided design of expanded granular sludge bed (EGSB) bioreactors. Ind Chem Engr. 2008;50:122-8.

\section{Publisher's Note}

Springer Nature remains neutral with regard to jurisdictional claims in published maps and institutional affiliations. 